\title{
Simulation and Injection Molding of Ring-Shaped Polymer Bonded Nickel Braze Metal Composite Preforms Based on Rheological and Thermal Analyses
}

\author{
Stefan Kirchberg \\ Institute of Polymer Materials and Plastics Engineering, Clausthal University of Technology, Clausthal-Zellerfeld, Germany. \\ Email: stefan.kirchberg@tu-clausthal.de
}

Received March $7^{\text {th }}, 2013$; revised March $30^{\text {th }}, 2013$; accepted April $10^{\text {th }}, 2013$

Copyright (C) 2013 Stefan Kirchberg. This is an open access article distributed under the Creative Commons Attribution License, which permits unrestricted use, distribution, and reproduction in any medium, provided the original work is properly cited.

\begin{abstract}
Rheological and thermal properties of LD-PE and LD-PE +65 vol\% Ni composite were examined by viscosity, pvt and thermal conductivity measurements at a wide range of shear rate, temperature and pressure. The typical shear-thinning viscosity of LD-PE polymer melt was enhanced up to four times by adding $65 \mathrm{vol} \% \mathrm{Ni}$ braze metal particles. LD-PE show increasing specific volume versus temperature, decreasing with pressure and braze particle filler content. Variation of specific volume of LD-PE was reduced to $5 \%$ by admixing 65 vol\% rigid Ni braze metal particles. Thermal conductivity of LD-PE was increased up to 15 times in the composite, reduced by decreasing pressure at temperature exceeding $80^{\circ} \mathrm{C}$. Furthermore, thermal analysis was performed in modulated DSC to determine the specific heat capacity in wide temperature range. Viscosity and pvt-data were fitted using Cross-WLF equation and 2-domain Tait-pvt model, respectively. Simulation of LD-PE and LD-PE + 65 vol\% Ni composite was performed based on rheological and thermal properties to define processing parameters. Simulation and injection molding of ring-shaped LD-PE $+65 \mathrm{vol} \% \mathrm{Ni}$ composite braze metal preforms were performed successfully.
\end{abstract}

Keywords: Polymer-Particle Composite; Injection Molding; Simulation; Rheological Analysis; Thermal Analysis

\section{Introduction}

Polymer-particle composites attract great attention in scientific research and industrial applications, e.g. in electrical, magnetic or thermal devices and processes [1-6]. The functional properties of composites are custom-made adjustable by combining polymers and particles having optimized property profile and volume fraction in the composite [6]. The main advantage of polymer-particle composites is their easy and cost efficient process ability in injection molding even in case of complex structures. Hence, conventional materials and processes are substitutable, e.g. by injection molding of polymer bonded nickel based braze metal performs for high temperature brazing processes [6].

The flow behavior of polymer-particle composite melts is significantly affected by their particle content, which affects the process ability in melt processing [7]. The simulation of flow behavior of particle reinforced composites is a current research topic in polymer processing and complex fluid dynamics. However, the particle-particle and polymer-particle interactions in composites cannot be adequate reproduced in process simulation up to now. For industrial applications in automotive and electronic sector the macroscopic flow behavior of composites is the main driving force to produce complex functional high-end products by injection molding. Simulation software Autodesk ${ }^{\circledR}$ Moldflow $^{\circledR}$ is designed to determine the processing behavior of polymers and polymer bonded composites in flow processes. Therefore, multi-phase materials have to be reduced to a continuous single-phase material. Nevertheless, homogeneous distribution of particles (or fibers) in injection molded composite parts is mandatory for uniform material behavior.

Material properties (e.g. viscosity, pvt-behavior, thermal conductivity, specific heat capacity) of standard thermoplastic polymers are usually available from material database provided by the simulation software. In case of custom-made polymer-particle composites these properties are not included in standard databases. Thus, rheological and thermal properties of polymer bonded braze metal composites have to be analyzed and fitted to provide a material-specific database for simulation and in- 
jection molding of composite preforms, which has not been published in literature up to now.

In the last decades a large number of phenomenological and empirical models were established to describe the flow behavior of polymer melts. Based on the well-known Carreau model $[8,9]$ the Cross-WLF equation was found by Williams et al. [10] to describe the temperature and shear rate dependent viscosity $\eta(T, \dot{\gamma})$ of polymer melts [11]:

$$
\eta(T, \dot{\gamma})=\frac{\eta_{0}}{1+\left(\frac{\eta_{0} \cdot \dot{\gamma}}{\tau^{*}}\right)^{(1-n)}}
$$

with

$$
\eta_{0}=D_{1} \cdot \exp \left(\frac{-A_{1} \cdot\left(T-D_{2}\right)}{A_{2}+\left(T-D_{2}\right)}\right)
$$

The zero shear viscosity $\eta_{0}$ describes the Newtonian plateau in which the viscosity approaches a constant at very low shear rates. Furthermore, $\dot{\gamma}$ is the shear rate, $\tau^{*}$ is the critical stress level at the transition to shear thinning, $n$ is the power law index in the high shear rate regime, $D_{1}, A_{1}$ and $A_{2}$ are data-fitted coefficients and $D_{2}$ is the glass transition temperature.

The pressure-volume-temperature (pvt) behavior of amorphous polymers was modeled and experimental investigated by Chang et al. [12]. The 2-domain Tait-pvt model is used to account the material compressibility during a flow simulation. The specific volume $v(p, T)$ is a function of temperature $T$ and pressure $p$ described for semi-crystalline polymers as follows:

$$
\begin{aligned}
& v(p, T) \\
& =v_{0}(p, T) \cdot(1-0.0894 \cdot \ln [1+p / B(T)])+v_{t}(p, T)
\end{aligned}
$$

At temperatures above transition temperature $\left(T>T_{t}(p)\right)$ Equation (3) can be written as:

$$
\begin{aligned}
& v(p, T)=\left(b_{1 m}+\left(b_{2 m} \cdot\left(T-b_{5}\right)\right)\right) \\
& \cdot\left(1-\left(0.0894 \cdot \ln \left(1+\left(\frac{p}{b_{3 m} \cdot \exp \left(b_{4 m} \cdot T-b_{5}\right)}\right)\right)\right)\right)
\end{aligned}
$$

At temperatures below transition temperature $\left(T<T_{t}(p)\right)$ Equation (3) is given as:

$$
\begin{aligned}
& v(p, T)=\left(b_{1 m}+\left(b_{2 m} \cdot\left(T-b_{5}\right)\right)\right) \\
& \cdot\left(1-\left(0.0894 \cdot \ln \left(1+\left(\frac{p}{b_{3 m} \cdot \exp \left(b_{4 m} \cdot T-b_{5}\right)}\right)\right)\right)\right)+v_{t}(p, T)
\end{aligned}
$$

with

$$
v_{t}(p, T)=b_{7} \cdot \exp \left(\left(b_{8} \cdot\left(T-b_{5}\right)\right)-\left(b_{9} \cdot p\right)\right)
$$

The physical meaning of the parameters used in Equations (4)-(6) is described in Table 1.

\section{Materials and Methods}

Low density Polyethylene (LD-PE, Lupolen 1806 H, Lyondellbasell, Ludwigshafen, Germany) with a specific density of $0.919 \mathrm{~g} / \mathrm{cm}^{3}$ was chosen as semi-crystalline thermoplastic polymer matrix.

Spherical nickel $(\mathrm{Ni})$ braze metal powder (B-Ni82CrSiBFe970/1000, Womet GmbH, Willich, Germany) with typical particle size distribution from $10 \mu \mathrm{m}$ to 106 $\mu \mathrm{m}$ (see Figure 1) and specific density of $7.7 \mathrm{~g} / \mathrm{cm}^{3}$ was selected as filler particles. Figure 1 shows sum allocation

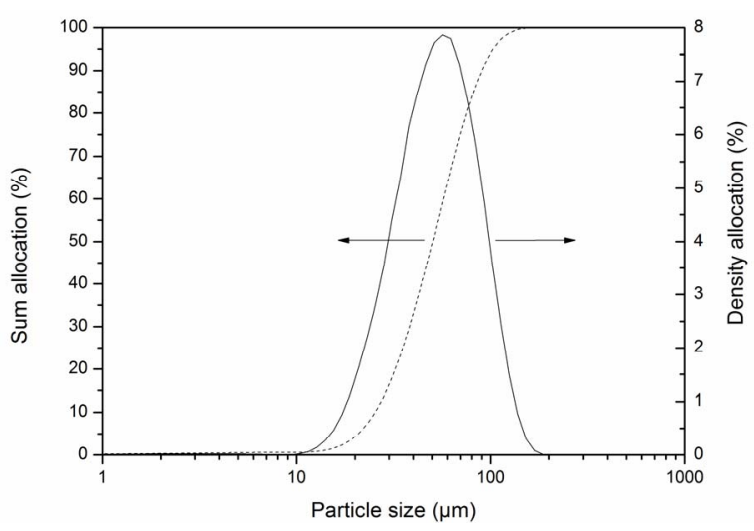

Figure 1. Particle size distribution of braze metal particles.

Table 1. Physical meaning of the parameters used in the 2domain Tait-pvt model [12].

\begin{tabular}{cc}
\hline Parameter & Physical meaning \\
\hline $\mathrm{b}_{1 m}$ & Intercept of melt-state v-T line at $p=0$ \\
$\mathrm{~b}_{2 m}$ & Slope of melt-state v-T line at $p=0$ \\
$\mathrm{~b}_{3 m}$ & Pressure sensitivity above $T_{t}$ (line drop) \\
$\mathrm{b}_{4 m}$ & Pressure sensitivity above $T_{t}$ (slope change) \\
$\mathrm{b}_{1 s}$ & Intercept of solid-state $\mathrm{v}_{\mathrm{sp}}$-T line at $p=0$ \\
$\mathrm{~b}_{2 s}$ & Slope of solid-state v-T line at $p=0$ \\
$\mathrm{~b}_{3 s}$ & Pressure sensitivity below $T_{t}$ (line drop) \\
$\mathrm{b}_{4 s}$ & Pressure sensitivity below $T_{t}$ (slope change) \\
$\mathrm{b}_{5}$ & Glass transition temperature at $p=0$ \\
$\mathrm{~b}_{6}$ & Rate of change of $T_{t}$ with pressure \\
$\mathrm{b}_{7}$ & Radius of curvature below $T_{t}$ \\
$\mathrm{~b}_{8}$ & Radius of curvature below $T_{t}$ \\
$\mathrm{~b}_{9}$ & Change of curvature radius with pressure below $T_{t}$ \\
\hline
\end{tabular}


and mono-modal density allocation of Ni braze metal powder.

LD-PE and pre-heated $\left(100^{\circ} \mathrm{C}\right)$ braze metal microparticles were compounded for $10 \mathrm{~min}$ at $200^{\circ} \mathrm{C}$ and $50 \mathrm{rpm}$ in a co-rotating lab kneader (PolyLab Rheomix 600 p, ThermoHaake, Thermo Fisher Scientific, Karlsruhe, Germany) to LD-PE + 65 vol\% Ni composite. LD-PE and Ni particles were dosed gravimetrically using a laboratory balance (Aculab Arilon, Sartorius GmbH, Göttingen, Germany).

Viscosity, pvt-behavior ( $p=$ pressure, $v=$ specific volume, $T=$ temperature) and thermal conductivity of LD$\mathrm{PE}$ and LD-PE +65 vol\% Ni were characterized using high shear capillary rheometer (Rheograph 75, Goettfert Werkstoff-Pruefmaschinen GmbH, Germany). Viscosity was determined from apparent viscosity using Bagleyand Rabinowitsch-Weissenberg corrections. Pvt-behavior and thermal conductivity were analyzed in script-controlled methods. Specific heat capacity was analyzed by modulated differential scanning calorimeter (MDSC Q2000, TA Instruments, Alzenau, Germany) in temperature range between $20^{\circ} \mathrm{C}$ and $200^{\circ} \mathrm{C}$ with heating rate of $3^{\circ} \mathrm{C} / \mathrm{min}$ and temperature modulation of $0.48^{\circ} \mathrm{C} / \mathrm{min}$ under nitrogen atmosphere. For temperature calibration the melt temperature of indium, lead, tin and zinc standards have been measured to achieve a minimum temperature deviation of $0.2^{\circ} \mathrm{C}$. Autodesk ${ }^{\circledR}$ Moldflow $^{\circledR}$ (Insight) and OriginLab ${ }^{\circledR}$ (OriginPro8G) software were used to perform simulation and data fitting. The composite was granulated and further injection molded in multi-cavity tool to ring-shaped braze metal preforms $(44 \mathrm{~mm}$ inner diameter with $3 \mathrm{~mm}$ diameter in cross section, $10 \mathrm{~mm}$ inner diameter with 2 $\mathrm{mm}$ diameter in cross section) using a hydraulic injection molding machine (Arburg Allrounder 220S, Arburg, Lossburg, Germany).

\section{Results and Discussion}

Figure 2 shows the shear viscosity of LD-PE and LD-PE $+65 \mathrm{vol} \% \mathrm{Ni}$ composite at shear rate ranging from 11 to $5 \times 10^{4}(1 / \mathrm{s})$ and three different temperatures $\left(180^{\circ} \mathrm{C}\right.$, $200^{\circ} \mathrm{C}, 220^{\circ} \mathrm{C}$ ). The typical shear-thinning viscosity behavior of LD-PE increases significantly by adding 65 vol\% braze metal particles. Viscosity of the composite is up to four times higher than that of LD-PE, which consequently reduces flow ability in melt processing. Furthermore, viscosity of LD-PE and LD-PE + 65 vol\% Ni composite was shifted to lower values with increasing temperature. Similar behavior was measured on complex viscosity of $\mathrm{PP} / \mathrm{FeSi}$ composites at filler content up to 70 vol\% [7]. In general, processing temperature is limited by thermal degradation of the polymer matrix.

The viscosity behavior of LD-PE and LD-PE +65 vol\% Ni composite in Figure 2 was fitted using Cross-
WLF equation, mentioned in Equations (1) and (2).

The parameter of the Cross-WLF equation were determined by OriginLab ${ }^{\circledR}$ software and are mentioned in Table 2 for LD-PE and LD-PE + 65 vol\% Ni composite. The accuracy of the viscosity fitting was $99.99 \%$.

Figure 3 shows pvt ( $p=$ pressure, $v=$ specific volume, $t=$ temperature) behavior of LD-PE and LD-PE +65 vol\% Ni composite. Specific volume of LD-PE decreases with increasing pressure and decreasing temperature. In melt temperature range of LD-PE (approx. $110^{\circ} \mathrm{C}$ ) the pvt-behavior of LD-PE is characterized by declining specific volume compared to LD-PE +65 vol $\%$ Ni composite (cf. Figure 3), caused by the shrinkage of LD-PE while cooling from molten to solid state. Increasing filler content of rigid braze particles in composite reduces specific volume up to 6.5 times. The maximum variation in specific volume of LD-PE is $263 \mathrm{~mm}^{3} / \mathrm{g}$, whereas LD-PE +65 vol\% Ni composite shows a maximum specific volume range of $14 \mathrm{~mm}^{3} / \mathrm{g}$. Consequently, shrinkage of LD$\mathrm{PE}+65 \mathrm{vol} \% \mathrm{Ni}$ composite is approximately $5 \%$ of LD$\mathrm{PE}$, whereby replication quality of injection molded composite structures is improved by adding rigid braze metal particles. Since, specific density is defined as the inverse

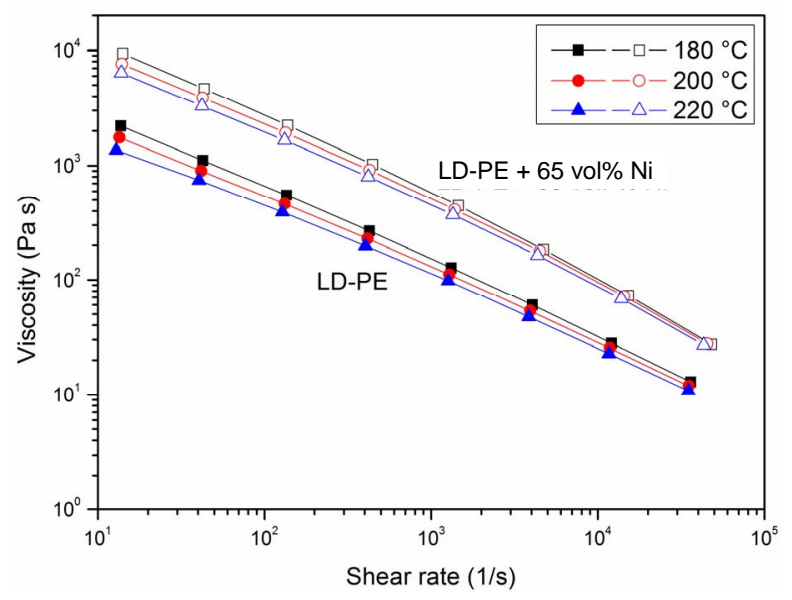

Figure 2. Effect of Ni braze particle content, shear rate and temperature on viscosity of LD-PE and LD-PE + $65 \mathrm{vol} \%$ Ni composite.

Table 2. Cross-WLF parameter of LD-PE and LD-PE + 65 vol\% Ni composite.

\begin{tabular}{ccc}
\hline Cross-WLF parameter & LD-PE & LD-PE +65 vol\% Ni \\
\hline$D_{1}$ & $1.23 \times 10^{9}$ & $1.46 \times 10^{9}$ \\
$D_{2}$ & 305.43 & 311.51 \\
$A_{1}$ & 21.67 & 20.42 \\
$A_{2}$ & 83.94 & 88.87 \\
$n$ & 0.38 & 0.35 \\
$\tau^{*}$ & 7450.17 & 39277.89 \\
\hline
\end{tabular}


specific volume, specific density of LD-PE and LD-PE + $65 \mathrm{vol} \% \mathrm{Ni}$ composite can be directly calculated from Figure 3.

The pvt-behavior of LD-PE and LD-PE + 65 vol\% Ni composite in Figure 3 was fitted using 2-domain Taitpvt model described in Equations (3)-(6). The parameters of the Tait-pvt model were determined by global fitting in OriginLab ${ }^{\circledR}$ software and listed in Table 3 for LD-PE and LD-PE $+65 \mathrm{vol} \% \mathrm{Ni}$ composite. The global fitting of the pvt-behavior was performed with an accuracy of $99.6 \%$.

Thermal conductivity of LD-PE was significantly increased by adding high conductive braze metal particles to the polymer matrix (cf. Figure 4). Thermal conductivity of LD-PE shows almost constant and relatively low values between 0.2 and $0.5 \mathrm{~W} /(\mathrm{m} \cdot \mathrm{K})$ having minor pressure-dependent variations particularly in melt temperature range around $110^{\circ} \mathrm{C}$. Adding braze metal particles to LD-PE increases thermal conductivity up to $3 \mathrm{~W} /(\mathrm{m} \cdot \mathrm{K})$

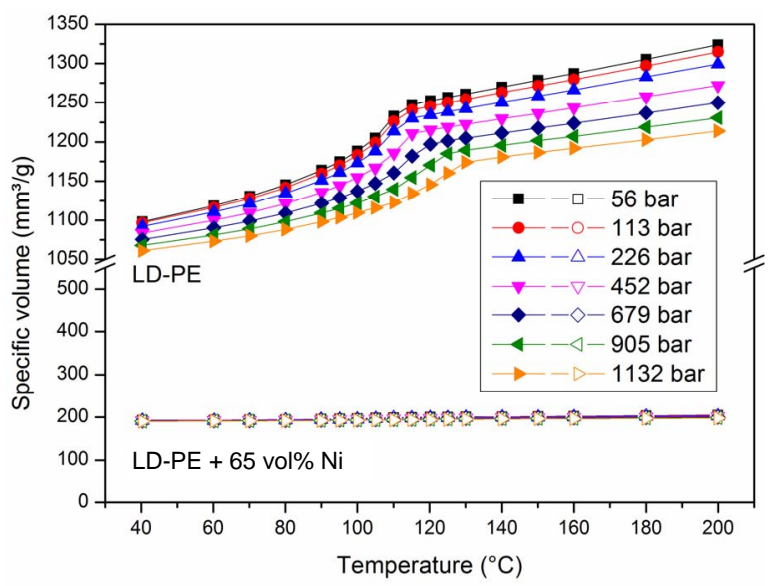

Figure 3. Effect of Ni braze metal particle content on pvtbehavior of LD-PE and LD-PE + 65 vol\% Ni composite.

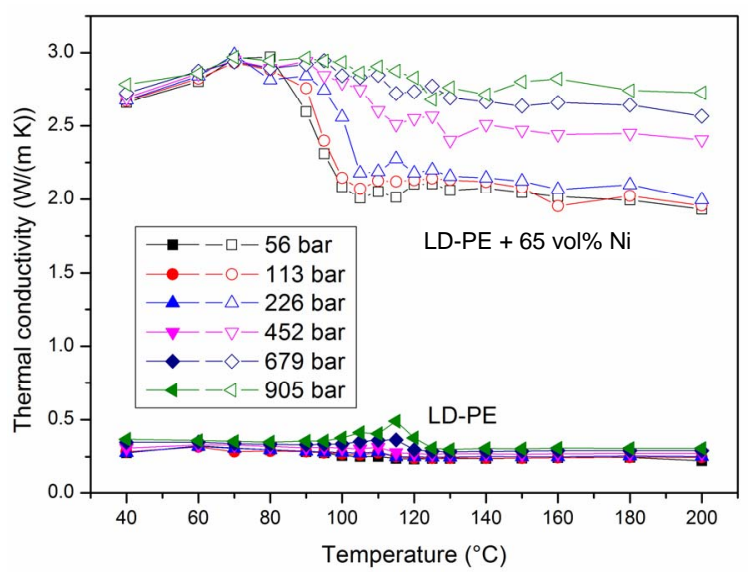

Figure 4. Effect of Ni braze metal particle content, temperature and pressure on thermal conductivity of LD-PE and LD-PE + 65 vol\% Ni composite. caused by the high thermal conductivity of nickel braze metal $(91 \mathrm{~W} /(\mathrm{m} \cdot \mathrm{K}))$. Thermal conductivity of LD-PE + $65 \mathrm{vol} \% \mathrm{Ni}$ composite is not significantly affected by pressure and slightly affected by temperature up to temperature of $80^{\circ} \mathrm{C}$. Exceeding this temperature results in pressure-dependent thermal conductivity of LD-PE + 65 vol\% Ni composite caused by softening of the polymer matrix. Hence, high thermal conductivity fastens cooling and reduces mold filling time in injection molding process. This can be compensated by increased temperature of the injection mold to reduce the temperature gradient between melt and mold.

Figure 5 shows specific heat capacity $\left(c_{p}\right)$ of LD-PE, which is characterized by a broad peak caused by the melting

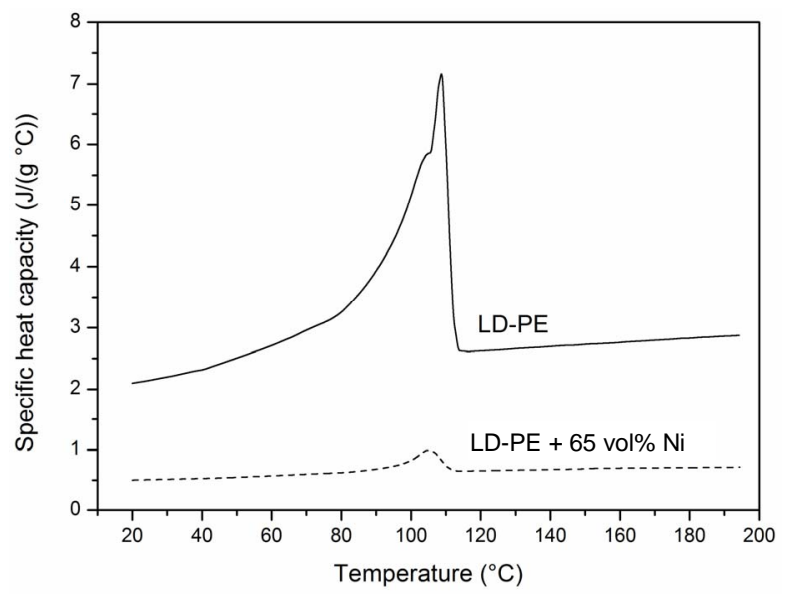

Figure 5. Effect of Ni braze metal particle content and temperature on specific heat capacity of LD-PE and LD-PE + 65 vol\% Ni composite.

Table 3. Tait-pvt parameter of LD-PE and LD-PE +65 vol\% Ni composite.

\begin{tabular}{ccc}
\hline Tait parameter & LD-PE & LD-PE +65 vol $\% \mathrm{Ni}$ \\
\hline$b_{1 s}$ & 1173.07 & 193.82 \\
$b_{1 m}$ & 1255.02 & 199.67 \\
$b_{2 s}$ & 1.01 & 0.012 \\
$b_{2 m}$ & 0.87 & 0.062 \\
$b_{3 s}$ & $1.22 \times 10^{8}$ & $9.29 \times 10^{8}$ \\
$b_{3 m}$ & $7.8 \times 10^{7}$ & $2.9 \times 10^{8}$ \\
$b_{4 s}$ & 0.0085 & $6.2 \times 10^{-4}$ \\
$b_{4 m}$ & $9.15 \times 10^{-4}$ & $3 \times 10^{-3}$ \\
$b_{5}$ & 385 & 385 \\
$b_{7}$ & 80.82 & 7.02 \\
$b_{8}$ & 0.069 & 0.05 \\
$b_{9}$ & $1.0 \times 10^{-8}$ & $1.4 \times 10^{-8}$ \\
\hline
\end{tabular}


of the semi-crystalline polymer structure. Melting is an endothermic process, whereas heat capacity increases rapidly. Above melt temperature heat capacity shows slightly linear increase with temperature. In case of LD-PE + $65 \mathrm{vol} \% \mathrm{Ni}$ composite the melting peak in heat capacity is significantly reduced caused by lower LD-PE content (35 vol\%).

Based on the experimental data, illustrated in Figures 2-5, as well as Cross-WLF viscosity fitting and Tait-pvt data fitting the flow behavior of LD-PE and LD-PE +65 vol\% Ni composite were obtained in simulation. Simulation results were created by Autodesk ${ }^{\circledR}$ Moldflow ${ }^{\circledR}$ software. The drawing of ring-shaped multi-cavity was meshed by triangular elements of about $5 \mathrm{~mm}$ edge length using solid 3-D meshing. Furthermore, melt temperature of $200^{\circ} \mathrm{C}$, flow rate of $22 \mathrm{~cm}^{3} / \mathrm{s}$ and demolding temperature $\left(40^{\circ} \mathrm{C}\right)$ were kept constant regarding to the processing requirements. The simulation was conducted at varying injection pressure (up to 2500 bar) and mold temperature until the ring-shaped multi-cavity was completely filled by LD-PE and LD-PE +65 vol\% $\mathrm{Ni}$ composite. The final processing parameters are listed in Table 4. Injection pressure of LD-PE $+65 \mathrm{vol} \% \mathrm{Ni}$ composite is four times higher than that of LD-PE, whereas mold temperature increased from $30^{\circ} \mathrm{C}$ to $80^{\circ} \mathrm{C}$.

Variation in processing parameters of LD-PE and LD$\mathrm{PE}+65 \mathrm{vol} \% \mathrm{Ni}$ composite are affected by viscosity and thermal conductivity results, illustrated in Figures 2 and 4. Increasing injection pressure induce higher shear rate, whereby viscosity of LD-PE +65 vol\% Ni composite will be reduced. Furthermore, increasing mold temperature from $30^{\circ} \mathrm{C}$ to $80^{\circ} \mathrm{C}$ reduces temperature gradient between melt $\left(200^{\circ} \mathrm{C}\right)$ and mold, which extends filling time while injecting LD-PE +65 vol\% Ni composite with relatively high thermal conductivity.

Injection molding experiments were conducted using processing parameter sets in Table 4. Figure 6 shows simulation (top) and injection molded (bottom) ring-shaped LD-PE + 65 vol\% Ni composite braze preforms in comparison. The composite melt flows through the sprue and the central inlets into the ring-shaped molds, where it will be divided into two flow fronts, which meets on the opposite side of each ring. Both, simulation and injection

Table 4. Processing parameters.

\begin{tabular}{rcc}
\hline & LD-PE & LD-PE +65 vol\% Ni \\
\hline Melt temperature in ${ }^{\circ} \mathrm{C}$ & 200 & 200 \\
Flow rate in $\mathrm{cm}^{3} / \mathrm{s}$ & 22 & 22 \\
Injection pressure in bar & 500 & 2000 \\
Mold temperature in ${ }^{\circ} \mathrm{C}$ & 30 & 80 \\
\hline
\end{tabular}

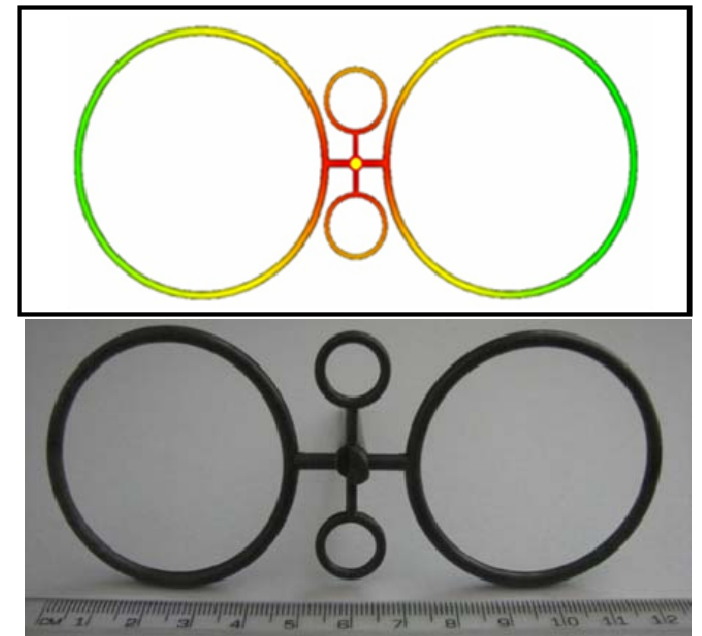

Figure 6. Flow simulation (top) and injection molded (bottom) ring-shaped LD-PE + 65 vol\% Ni composite preforms.

molding on ring-shaped LD-PE (not shown) and LD-PE $+65 \mathrm{vol} \% \mathrm{Ni}$ composite preforms were successfully performed based on (fitted) material data and selected processing parameters.

\section{Conclusion}

Viscosity, pvt-behavior, thermal conductivity and specific heat capacity of LD-PE and LD-PE + 65 vol\% Ni composite were investigated in process-specific parameter range. Viscosity of LD-PE was increased up to four times by adding 65 vol\% Ni braze metal particles. Pvt measurements of LD-PE $+65 \mathrm{vol} \% \mathrm{Ni}$ composite show up to 6.5 times lower values and up to 20 times lower variation of specific volume compared to LD-PE. Consequently, material shrinkage is significantly reduced by adding rigid Ni braze metal particles. Thermal conductivity of LD-PE increases up to 15 times in the composite, affecting cooling behavior and filling time in injection molding process. Specific heat capacity of LD-PE show polymer-specific melting peak and slightly increase with temperature. Viscosity and pvt-behavior of LD-PE and LD-PE +65 vol $\%$ Ni composite were fitted by CrossWLF equation and 2-domain Tait-pvt model, respectively. Fitted material data and thermal properties were further used in simulation to define processing parameters for injection molding of ring-shaped polymer bonded nickel braze metal preforms. Simulation and injection molding of ring-shaped LD-PE $+65 \mathrm{vol} \% \mathrm{Ni}$ composite preforms were performed successfully in multi-cavity tool.

\section{Acknowledgements}

The author would like to thank the Deutsche Forschungsgemeinschaft (DFG) for financial support (Project No. KI 1656/1-1). 


\section{REFERENCES}

[1] D. M. Bigg, "Electrical Properties of Metal-Filled Polymer Composites," In: S. K. Bhattacharya, Ed., Metal-Filled Polymers: Properties and Applications, Dekker, New York, 1986, pp. 165-226.

[2] S. T. Tan, M. Q. Zhang, M. Z. Rong and H. M. Zeng, "Effect of Interfacial Modification on Metal Fiber Filled Polypropylene Composites and Property Balance," Polymer Composites, Vol. 20, No. 3, 1999, pp. 406-412. doi:10.1002/pc.10366

[3] T. Katsura, M. R. Kamal and L. A. Utracki, "Some Properties of Polypropylene Filled with Metal Fibers," Polymer Composites, Vol. 6, No. 4, 1985, pp. 282-285. doi:10.1002/pc.750060413

[4] M. Y. Razzaq, M. Anhalt, B. Weidenfeller and L. Frormann, "Thermal, Electrical and Magnetic Studies of Magnetite Filled Polyurethane Shape Memory Polymers," Material Science and Engineering: Part A, Vol. 444, No. 1-2, 2007, pp. 227-235. doi:10.1016/j.msea.2006.08.083

[5] M. Sarasa, D. Gerling, G. Kastinger and A. Schumacher, "Soft Magnetic Materials for Electrical Machines," Joint Czech Polish Conference on Project GACR430813, Low Voltage Electrical Machines, Brünn, 12-13 November 2003, pp. 91-98.

[6] S. Kirchberg, U. Holländer, K. Möhwald, G. Ziegmann and F.-W. Bach, "Processing and Characterization of Injection Moldable Polymer-Particle Composites Applicable in Brazing Processes," Journal of Applied Polymer Science,

\section{2. doi:10.1002/app.38862}

[7] S. Kirchberg and G. Ziegmann, "Effect of Spherical Iron Silicon (FeSi) Microparticles on the Viscosity Behaviour of Polypropylene Melt," Applied Rheology, Vol. 21, No. 3, 2011, pp. 1-8.

[8] R. B. Bird and P. J. Carreau, "A Nonlinear Viscoelastic Model for Polymer Solutions and Melts: Part I," Chemical Engineering Science, Vol. 23, No. 5, 1968, pp. 427-434. doi:10.1016/0009-2509(68)87018-6

[9] P. J. Carreau, I. F. MacDonald and R. B. Bird, "A Nonlinear Viscoelastic Model for Polymer Solutions and Melts: Part II," Chemical Engineering Science, Vol. 23, No. 8, 1968, pp. 901-911. doi:10.1016/0009-2509(68)80024-7

[10] M. L. Williams, R. F. Landel and J. D. Ferry, "The Temperature Dependence of Relaxation Mechanisms in Amorphous Polymers and Other Glass-Forming Liquids," Journal of the American Chemical Society, Vol. 77, No. 14, 1955, pp. 3701-3707. doi:10.1021/ja01619a008

[11] M. M. Cross, "Relation between Viscoelasticity and ShearThinning Behaviour in Liquids," Rheologica Acta, Vol. 18, No. 5, 1979, pp. 609-614. doi:10.1007/BF01520357

[12] R. Y. Chang, C. H. Chen and K. S. Su, "Modifying the Tait Equation with Cooling-Rate Effects to Predict the Pressure-Volume-Temperature Behaviors of Amorphous Polymers: Modeling and Experiments," Polymer Engineering and Science, Vol. 36, No. 13, 1996, pp. 1789-1795. doi:10.1002/pen.10574 